\title{
Effect of Storage Conditions and Time on the Polyphenol Content of Wheat Flours
}

\author{
Yanxin Zhang, Francesca Truzzi *, Eros D’Amen and Giovanni Dinelli \\ Department of Agricultural and Food Sciences, Alma Mater Studiorum-University of Bologna, \\ 40127 Bologna, Italy; yanxin.zhang2@unibo.it (Y.Z.); eros.damen2@unibo.it (E.D.); \\ giovanni.dinelli@unibo.it (G.D.) \\ * Correspondence: francesca.truzzi3@unibo.it; Tel.: +39-051-209-6674
}

check for updates

Citation: Zhang, Y.; Truzzi, F.; D'Amen, E.; Dinelli, G. Effect of Storage Conditions and Time on the Polyphenol Content of Wheat Flours. Processes 2021, 9, 248. https:// doi.org/10.3390/pr9020248

Received: 28 December 2020

Accepted: 25 January 2021

Published: 29 January 2021

Publisher's Note: MDPI stays neutral with regard to jurisdictional claims in published maps and institutional affiliations.

Copyright: (C) 2021 by the authors Licensee MDPI, Basel, Switzerland. This article is an open access article distributed under the terms and conditions of the Creative Commons Attribution (CC BY) license (https:// creativecommons.org/licenses/by/ $4.0 /)$.
Abstract: Whole wheat flour possesses many nutritional properties because of its abundant bioactive components which are affected by cultivar, but little attention is paid to its relationship with storage conditions. In this study, phenolic extracts of whole wheat flour from four cultivars stored under different conditions (aerated and under vacuum) and different times (0, 2, 4, 8 weeks) were obtained. The total polyphenol (TPC) and flavonoid (TFC) contents, composition of phenolic acids, and antioxidant activities (AA) of phenolic extracts were evaluated. The results showed that Verna exhibited the highest levels of TPC, TFC, and AA for both storage conditions among the four cultivars. Moisture content, TFC, and AA fluctuated during storage. After 8 weeks, the TPC, TFC, and AA decreased with respect to Week 0 in all the cultivars. The TPC losses ranged between $16.39 \%$ and $20.88 \%$ and TFC losses from $14.08 \%$ to $31.18 \%$. The AA losses were approximately $30 \%$ from the DPPH assay, but no significant losses were shown in the FRAP assay. However, these parameters were not distinctive between the two storage conditions. The wheat phenolic acid profiles were influenced more by storage time than storage conditions in all cultivars. Overall, the results validate the effect of the storage time on wheat polyphenol.

Keywords: whole wheat flour; phenolic extracts; storage conditions; storage time; antioxidant activity

\section{Introduction}

Wheat is one of the most important food materials in people's daily diet worldwide, providing calories from carbohydrates and proteins. There is increasing interest in the health benefits associated with the consumption of whole grain food, related to the presence of fiber and bioactive phytochemicals, such as phenolic acids, tocopherols, carotenoids, and so on. Most of these bioactive compounds are found in the outer layer of the wheat kernel (aleurone, bran, and germ), thereby forming the ingredients of whole wheat flour and, in so doing, providing more antioxidant benefits than refined flour [1]. Increasingly more evidence has shown that whole grain flour may help to reduce the risk of cardiovascular disease, chronic diseases, and cancer [2,3].

Phenolic compounds are cited as the most important contributors to antioxidant activity in wheat. These components, which contain hydroxyl groups connected to aromatic rings, can efficiently react and stabilize free radicals [4]. Phenolic compounds are secondary plant metabolites containing one or more aromatic rings attached to one or more hydroxyl groups [5]. Phenolic acids in wheat are mainly present in three forms: soluble free acids, soluble conjugated forms with sugars or other low molecular weight compounds, and insoluble bound forms which are connected to the fiber fraction [6]. Hydroxycinnamic acids are the dominant phenolic compound in whole wheat, among which ferulic acid is the most abundant type, accounting for 70-90\%, followed by caffeic acid, $p$-coumaric acid, and sinapic acid. There are also benzoic acid derivatives which include protocatechuic acid, p-hydroxybenzoic acid, salicylic acid, vanillic acid, and syringic acid [6]. 
The content of these bioactive components is affected by genotype, cultivar, and the part of the grain sampled. There are many studies on the effects of genotype and environment on phenolic acid content and profiles in wheat and wheat products [7]. Many different factors influence the content of these compounds, such as stress conditions, both biotic and abiotic [8]. A few stresses can significantly increase their content [9]. In addition, a dwarf or semi-dwarf gene was introduced to modern wheat which led to high yields and improvement of disease and pest resistance [5] rather than of nutritional properties. Nowadays more attention has been given to health benefits from introducing bioactive components in the daily diet, leading to a renewed interest in the selection of varieties, including ancient cultivars, regarding their nutritional potentials. According to the report of Loreto et al. [5], significant differences in the content of phenolic acids were observed between ancient and modern durum wheat. Gotti et al. [7] found that ancient varieties of common wheat showed higher amount of the main represented phenolic acids than modern ones.

Phenolic compounds are not totally stable and are easily degraded during storage after harvest. Subsequently, their biological activity may be altered [10]. Oliveira et al. [11] found that there was a reduction in all phenolic compounds in both sorghum grain and flour within the first 60 days of storage, and that the retention of phenols ranged from $89.4 \%$ to $100 \%$ after 180 days of storage. Lang et al. [12] evaluated the influence of storage conditions on black rice phenolic compounds, showing an increase in total flavonoid content in the free form and a decrease in the bound part in grains stored under conventional and vacuum conditions, as well as illustrating a decrease in the total phenolics content regardless of the storage conditions. Whole wheat flour is more likely to be subject to rapid oxidization because lipids, lipase, and lipoxygenase are also contained in the germ and bran [10]. Few studies have focused on the phytochemical and biological activity losses in wheat flour during storage. This aspect necessitates further study.

The longevity of seeds depends on storage conditions such as seed moisture, oxygen, and temperature. The effects of oxygen are variable, depending on crop species and storage conditions. According to the study of Chiu et al. [13], partial vacuum storage could reduce ROS-mediated peroxidative damage during storage and improve the longevity of primed sweet corn (Zea mays L.) seeds. A paper bag is a normal mode to store wheat flour. Often, wheat flour must be stored for a few weeks in the kitchen. Little attention is paid to the longevity of the flour of seeds, especially the effect of oxygen in the storage atmosphere. In addition, due to the differences in wheat polyphenol content in different genotypes, it was important to select a cultivar with a high nutritional potential. The objectives of the present work were to study the effect of storage in air and under vacuum conditions at different storage times on phenolic compounds and the antioxidant capacities of extracts from different wheat cultivars. Verna and Timilia were representative ancient wheat cultivars used in the present study, whereas Sagittario and Claudio were the representatives of modern varieties.

\section{Materials and Methods}

\subsection{Chemicals and Reagents}

Vanillic acid, $p$-hydroxybenzoic acid, ferulic acid, $p$-coumaric acid, sinapic acid, and syringic acid (used as standard) were purchased from Sigma-Aldrich (Milan, Italy). Methanol, acetic acid, and water (HPLC-grade, Lichrosolv ${ }^{\circledR}$ ) were acquired from Merck (Darmstadt, Germany). All other chemicals and solvents were analytical grade.

\subsection{Wheat Samples}

Wheat samples consisted of two ancient (Verna and Timilia) and two modern (Sagittario and Claudio) Italian wheat cultivars, in which Verna and Sagittario were the representative common wheat (Triticum aestivum L.) genotypes and Timilia and Claudio were the representative durum wheat (Triticum turgidum ssp. Durum) genotypes, respectively. Grains were harvested from the same location in Italy (Argelato, latitude $44^{\circ} 39^{\prime} 57^{\prime \prime} \mathrm{N}$, longitude 
$11^{\circ} 19^{\prime} 43^{\prime \prime}$ E, $25 \mathrm{~m}$ a.s.1.) in the growing season 2018-2019 in organic agriculture. Whole wheat flour of each variety was obtained from a stone mill. The flour was stored in paper milling bags, commonly used for the storage of flour in aerated conditions, and plastic bags for vacuum conditions at an ambient temperature ranging from 25 to $30{ }^{\circ} \mathrm{C}$. After milling, the flour was measured immediately at week 0 . The analyses were repeated after different storage intervals $(2,4$, and 8 weeks) to simulate a time range of home practice and to evaluate the effects of storage time and storage conditions on the phenolic content and antioxidant activity.

\subsection{Extraction of Free and Bound Polyphenol}

The extraction of free and bound phenolic compounds was performed as previously described by Dinelli et al. [14]. Whole wheat flours $(1 \mathrm{~g})$ were added to $10 \mathrm{~mL}$ of cold $80 \%$ ethanol $\left(4^{\circ} \mathrm{C}\right)$ to obtain the free soluble compounds, followed by further hydrolysis extraction steps using sodium hydroxide and hydrochloric acid to release the bound fractions. The free and bound extracts were pooled together, evaporated to dryness, and reconstituted to a final volume of $4 \mathrm{~mL}$ in $70 \%$ ethanol. The extracts were filtered through a $0.45 \mu \mathrm{m}$ PTFE membrane filter and stored at $-20{ }^{\circ} \mathrm{C}$ until analysis.

\subsection{Determination of Total Polyphenol Content}

The TPC of extracts was determined according to the Folin-Ciocalteu method [15]. Briefly, $40 \mu \mathrm{L}$ of diluted phenolic extract was mixed with $1.6 \mathrm{~mL}$ of distilled water and $100 \mu \mathrm{L}$ of Folin-Ciocalteu reagent. After incubation for $5 \mathrm{~min}, 300 \mu \mathrm{L}$ of aqueous sodium carbonate solution $(0.2 \mathrm{~g} / \mathrm{mL})$ was added. The absorbance was measured at $765 \mathrm{~nm}$ after $2 \mathrm{~h}$ incubation in the dark. The TPC was expressed as $\mathrm{mg}$ of gallic acid equivalents (GAE) per $100 \mathrm{~g}$ of whole wheat flour.

\subsection{Determination of Total Flavonoids Content}

TFC was estimated using a colorimetric method described previously by Adom et al. [16]. Briefly, $250 \mu \mathrm{L}$ of diluted phenolic extract was added to $1.25 \mathrm{~mL}$ of distilled water and $75 \mu \mathrm{L}$ of sodium nitrite $(5 \%)$ and then incubated for $6 \mathrm{~min}$. There was a reaction with aluminum chloride $(10 \%)$ to form a flavonoid-aluminum complex within 5 min of incubation. Thereafter, $0.5 \mathrm{~mL}$ of $1 \mathrm{M}$ sodium hydroxide was added to stop the reaction. The absorbance was immediately measured at $510 \mathrm{~nm}$. The TFC was expressed as mg catechin equivalents (CE) per $100 \mathrm{~g}$ of whole wheat flour.

\subsection{HPLC-MS/MS Analysis}

A Waters e2695 Alliance HPLC System combined with a Waters ACQUITY QDa Mass Detector were used for the phenolic profile analysis, as described by Truzzi [17]. A Luna Omega C-18 (250 × $4.6 \mathrm{~mm}, 5 \mu \mathrm{m})$ (Phenomenex, CA, USA) column was used with a temperature at $40{ }^{\circ} \mathrm{C}$. The mobile phase was solvent $\mathrm{A}$ : water $+0.1 \%$ acetic acid and solvent B: methanol. A gradient experiment was conducted as follows: at 0 min, 20\% solvent B; at $2 \mathrm{~min}, 30 \%$ solvent B; at $10 \mathrm{~min}, 38 \%$ solvent B; at $17 \mathrm{~min}, 20 \%$ solvent $\mathrm{B}$. The flow rate and the injection volume were $1.2 \mathrm{~mL} / \mathrm{min}$ and $10 \mu \mathrm{L}$, respectively. Single-ion recording (SIR) was used in the Electrospray Ionization ESI negative mode, with cone voltage ( $8 \mathrm{~V})$, Probe $\left(600{ }^{\circ} \mathrm{C}\right)$, sampling rate $(10$ points / sec), capillary (Pos: 0.8, Neg: 0.8). The monitored (MH)-ions were $\mathrm{m} / \mathrm{z}$ 136.88, 162.93, 167.00, 192.93, 196.94, and 223.09 for $p$-hydroxybenzoic acid, $p$-coumaric acid, vanillic acid, ferulic acid, syringic acid, and sinapic acid, respectively. Data acquisition and instrument control were performed using the Empower 3 software.

\subsection{Assay of Antioxidant Activity in Vitro}

\subsubsection{Assay of DPPH Radical Scavenging Activity}

The DPPH assay was performed following a modified procedure reported by Floegel et al. [18]. Briefly, $1 \mathrm{~mm}$ of DPPH solution in $80 \%(v / v)$ methanol was prepared, for which of the absorbance was adjusted to $0.650 \pm 0.020$ at $517 \mathrm{~nm}$. Diluted phenolic extract 
$(50 \mu \mathrm{L})$ was added to $2.95 \mathrm{~mL}$ of DPPH solution. After incubation for $30 \mathrm{~min}$ in the dark, the absorbance was measured at $517 \mathrm{~nm}$. The results were expressed as $\mu \mathrm{mol}$ of Trolox equivalents (TE) per $g$ of whole wheat flour.

\subsubsection{Assay of Ferric Reducing Antioxidant Potential (FRAP)}

The FRAP assay was conducted according to Benzie and Strain [19], with some modifications. The freshly prepared FRAP working solution (WS) consisted of $300 \mathrm{~mm}$ of acetate buffer pH 3.6, $10 \mathrm{~mm}$ of TPTZ, and $20 \mathrm{~mm}$ of ferric chloride (10:1:1, v:v:v). A volume of $80 \mu \mathrm{L}$ of diluted $(1: 1, v / v)$ phenolic extracts was added to $2.4 \mathrm{~mL}$ of WS and incubated for $1 \mathrm{~h}$ in the dark. The absorbance was measured at $593 \mathrm{~nm}$. The results were expressed as $\mathrm{mmol} \mathrm{Fe}^{2+}$ per $100 \mathrm{~g}$ of whole wheat flour.

\subsection{Statistical Analysis}

Statistical analyses were performed using a one-way analysis of variance (ANOVA) test with the software SPSS, version 23.0 (SPSS Inc., Chicago, IL, USA). Statistical significance was considered at $p<0.05$. Results were expressed as the mean $\pm \mathrm{SD}$.

\section{Results}

\subsection{Moisture Content}

Water is an important composition of food, influencing the physical, chemical, and biological characteristics of food. The stability and shelf life of food is also affected by the water content. Water can enhance or weaken chemical reactions due to its effect on molecular mobility [20]. Since moisture content indicates the residual water in flours, this parameter is a crucial property of flour products. In the present study, the moisture content of the wheat flours was at a satisfactory level (ranging from $11.99 \%$ to $12.49 \%$ ) at Week 0 , as shown in Table 1 . The flours of the four cultivars under vacuum storage had a stable moisture content over 8 weeks of storage. Regarding the flour maintained in the air, the moisture content decreased at Week 2 compared with freshly prepared flour. However, there was an increase in moisture content from Week 4 to 8.

Table 1. The moisture content of four wheat genotypes stored under different conditions and for different lengths of time.

\begin{tabular}{cccccc}
\hline \multirow{2}{*}{ Cultivar } & \multirow{2}{*}{$\begin{array}{c}\text { Storage } \\
\text { Condition }\end{array}$} & Week 0 & Week 2 & Week 4 & Week 8 \\
\cline { 3 - 6 } & Air & $12.49 \pm 0.29 \% \mathrm{aA}$ & $11.04 \pm 0.11 \% \mathrm{cB}$ & $10.61 \pm 0.35 \% \mathrm{cdB}$ & $12.90 \pm 0.13 \% \mathrm{aA}$ \\
\multirow{2}{*}{ Verna } & Vacuum & $12.49 \pm 0.29 \% \mathrm{aA}$ & $12.35 \pm 0.08 \% \mathrm{aAB}$ & $11.96 \pm 0.33 \% \mathrm{aB}$ & $12.07 \pm 0.10 \% \mathrm{bAB}$ \\
& Air & $11.99 \pm 0.20 \% \mathrm{bB}$ & $10.84 \pm 0.00 \% \mathrm{cC}$ & $10.71 \pm 0.17 \% \mathrm{cC}$ & $12.69 \pm 0.19 \% \mathrm{aA}$ \\
\multirow{2}{*}{ Timilia } & Vacuum & $11.99 \pm 0.20 \% \mathrm{bA}$ & $11.76 \pm 0.15 \% \mathrm{bAB}$ & $11.57 \pm 0.16 \% \mathrm{abAB}$ & $11.53 \pm 0.32 \% \mathrm{cB}$ \\
& Air & $12.06 \pm 0.16 \% \mathrm{bB}$ & $10.97 \pm 0.27 \% \mathrm{cC}$ & $10.53 \pm 0.40 \% \mathrm{cdC}$ & $12.78 \pm 0.21 \% \mathrm{aA}$ \\
\multirow{2}{*}{ Sagittario } & Vacuum & $12.06 \pm 0.16 \% \mathrm{bA}$ & $11.61 \pm 0.44 \% \mathrm{bA}$ & $11.45 \pm 0.16 \% \mathrm{bA}$ & $11.98 \pm 0.39 \% \mathrm{bA}$ \\
& Air & $11.99 \pm 0.20 \% \mathrm{bB}$ & $10.89 \pm 0.18 \% \mathrm{cC}$ & $10.18 \pm 0.17 \% \mathrm{dC}$ & $12.51 \pm 0.04 \% \mathrm{aA}$ \\
\multirow{2}{*}{ Claudio } & Vacuum & $11.99 \pm 0.20 \% \mathrm{bA}$ & $11.65 \pm 0.28 \% \mathrm{bAB}$ & $11.31 \pm 0.29 \% \mathrm{bB}$ & $11.57 \pm 0.22 \% \mathrm{cAB}$ \\
& & &
\end{tabular}

Data are expressed as mean $\pm \mathrm{SD}(n=3)$. Different lowercase letters indicate significant differences in values at $p<0.05$. Values in the rows with different capital letters are significantly different at $p<0.05$.

\subsection{Total Polyphenol Content}

The TPC of freshly prepared whole wheat flour from the four cultivars ranged from 241.32 to 283.72 GAE mg/100 g (represented as Week 0 in Table 2). Verna exhibited a significantly higher phenolic content than the remaining three cultivars. 
Table 2. Total polyphenol contents expressed as gallic acid equivalents of four wheat cultivars (mg/100 g) stored under different conditions and lengths of time.

\begin{tabular}{cccccc}
\hline \multirow{2}{*}{ Cultivar } & \multirow{2}{*}{$\begin{array}{c}\text { Storage } \\
\text { Condition }\end{array}$} & Week 0 & Week 2 & Week 4 & Week 8 \\
\cline { 3 - 6 } & Air & $283.72 \pm 5.18 \mathrm{aA}$ & $282.72 \pm 8.31 \mathrm{aA}$ & $258.01 \pm 4.74 \mathrm{aB}$ & $236.06 \pm 6.13 \mathrm{bC}$ \\
\multirow{2}{*}{ Verna } & Vacuum & $283.72 \pm 5.18 \mathrm{aA}$ & $282.82 \pm 4.94 \mathrm{aA}$ & $260.41 \pm 7.74 \mathrm{aB}$ & $247.15 \pm 4.13 \mathrm{aC}$ \\
& Air & $273.41 \pm 4.29 \mathrm{aA}$ & $271.21 \pm 17.51 \mathrm{aA}$ & $233.83 \pm 3.38 \mathrm{bB}$ & $228.61 \pm 1.03 \mathrm{cB}$ \\
\multirow{2}{*}{ Timilia } & Vacuum & $273.41 \pm 4.29 \mathrm{aA}$ & $272.43 \pm 6.90 \mathrm{aA}$ & $239.08 \pm 3.70 \mathrm{bB}$ & $219.89 \pm 6.64 \mathrm{~dB}$ \\
& Air & $244.52 \pm 7.38 \mathrm{bA}$ & $211.33 \pm 6.86 \mathrm{bBC}$ & $216.50 \pm 7.24 \mathrm{cB}$ & $199.74 \pm 3.22 \mathrm{dC}$ \\
\multirow{2}{*}{ Sagittario } & Vacuum & $244.52 \pm 7.38 \mathrm{bA}$ & $217.32 \pm 3.19 \mathrm{bB}$ & $215.88 \pm 2.17 \mathrm{cB}$ & $200.75 \pm 2.13 \mathrm{dC}$ \\
& Air & $241.32 \pm 4.85 \mathrm{bA}$ & $216.20 \pm 4.19 \mathrm{bB}$ & $210.63 \pm 5.70 \mathrm{cdB}$ & $191.53 \pm 1.20 \mathrm{eC}$ \\
\multirow{2}{*}{ Claudio } & Vacuum & $241.32 \pm 4.85 \mathrm{bA}$ & $209.37 \pm 4.11 \mathrm{bB}$ & $204.23 \pm 4.29 \mathrm{~dB}$ & $190.93 \pm 3.08 \mathrm{eC}$ \\
\hline
\end{tabular}

Data are expressed as mean $\pm \operatorname{SD}(n=3)$. Different lowercase letters indicate significant differences in values at $p<0.05$. Values in the rows with different capital letters are significantly different at $p<0.05$.

The results illustrated that the TPC of the four cultivars was affected by the storage time. Overall, the TPC decreased significantly over the 8 weeks in all cultivars. Verna still showed the highest level of TPC. The rankings of the cultivars in order of increasing losses of TPC between Week 0 and Week 8 of storage were Timilia $<$ Verna $<$ Sagittario $<$ Claudio for aerated storage and Verna $<$ Sagittario $<$ Timilia $<$ Claudio for vacuum storage (with the corresponding percentages losses at 16.39, 16.80, 18.31, 20.63, and 12.89, 17.90, 19.57, 20.88 , respectively). There were no significant differences in TPC $(p<0.05)$ for the four cultivars between the air and vacuum storage conditions within the first 4 weeks. However, there was a significant difference in TPC between the air and vacuum storage conditions for Verna and Timilia at Week 8.

\subsection{Total Flavonoid Content}

In freshly prepared flour (represented as Week 0 in Table 3), the TFC of the four cultivars varied from 62.82 to $79.13 \mathrm{CE} \mathrm{mg/100} \mathrm{g.} \mathrm{Verna} \mathrm{had} \mathrm{the} \mathrm{highest} \mathrm{flavonoid} \mathrm{content}$ among the four cultivars.

Table 3. Total flavonoid contents expressed as catechin equivalents of four wheat cultivars (mg/100 g) stored under different conditions and for different lengths of time.

\begin{tabular}{cccccc}
\hline \multirow{2}{*}{ Cultivar } & Storage & \multicolumn{4}{c}{ Storage Time } \\
\cline { 2 - 5 } & Condition & Week 0 & Week 2 & Week 4 & Week 8 \\
\cline { 3 - 6 } & Air & $79.13 \pm 3.63 \mathrm{aA}$ & $58.72 \pm 2.17 \mathrm{aC}$ & $52.23 \pm 0.74 \mathrm{aD}$ & $67.36 \pm 1.37 \mathrm{aB}$ \\
\multirow{2}{*}{ Verna } & Vacuum & $79.13 \pm 3.63 \mathrm{aA}$ & $58.49 \pm 3.91 \mathrm{aC}$ & $52.98 \pm 1.01 \mathrm{aC}$ & $67.87 \pm 2.33 \mathrm{aB}$ \\
& Air & $69.09 \pm 1.31 \mathrm{bA}$ & $51.20 \pm 5.82 \mathrm{abcBC}$ & $45.74 \pm 1.09 \mathrm{cC}$ & $54.71 \pm 1.53 \mathrm{cB}$ \\
\multirow{2}{*}{ Timilia } & Vacuum & $69.09 \pm 1.31 \mathrm{bA}$ & $48.94 \pm 4.87 \mathrm{bcBC}$ & $44.89 \pm 1.74 \mathrm{cC}$ & $52.68 \pm 0.93 \mathrm{cB}$ \\
& Air & $71.24 \pm 1.68 \mathrm{bA}$ & $53.34 \pm 5.72 \mathrm{abC}$ & $48.36 \pm 0.83 \mathrm{bC}$ & $61.21 \pm 1.76 \mathrm{bB}$ \\
Sagittario & Vacuum & $71.24 \pm 1.68 \mathrm{bA}$ & $51.20 \pm 4.22 \mathrm{abcB}$ & $48.23 \pm 0.23 \mathrm{bB}$ & $52.32 \pm 3.36 \mathrm{cB}$ \\
& Air & $62.82 \pm 1.57 \mathrm{cA}$ & $45.47 \pm 0.97 \mathrm{cB}$ & $42.98 \pm 1.08 \mathrm{dC}$ & $47.24 \pm 0.32 \mathrm{~dB}$ \\
\multirow{2}{*}{ Claudio } & Vacuum & $62.82 \pm 1.57 \mathrm{cA}$ & $43.78 \pm 0.08 \mathrm{cB}$ & $40.76 \pm 0.46 \mathrm{eC}$ & $43.23 \pm 2.51 \mathrm{eBC}$ \\
& &
\end{tabular}

Data are expressed as mean $\pm \mathrm{SD}(n=3)$. Different lowercase letters indicate significant differences in values at $p<0.05$. Values in the rows with different capital letters are significantly different at $p<0.05$.

After 8 weeks, the TFC of all the cultivars decreased significantly when compared to the freshly prepared flour. Verna also showed the highest level of TFC. The TFC in Claudio decreased up to $31.18 \%$. However, there was a sharp increase from Week 4 to Week 8 for all cultivars. There were no significant differences in TFC between the air and vacuum storage conditions, with the exception of Claudio at Week 4 and Week 8 and Sagittario at Week 8. 


\subsection{Analysis of the Phenolic acid Profiles}

Six phenolic acids, including $p$-hydroxybenzoic acid, vanillic acid, syringic acid, $p$-coumaric acid, ferulic acid, and sinapic acid, were all found in the wheat flour of the four cultivars under the different storage conditions and lengths of time. Table 4 showed that the most abundant phenolic acid in the four cultivars was ferulic acid, which showed the highest mean value of $355.55 \mu \mathrm{g} / \mathrm{g}$. This was followed by $p$-coumaric acid, with a mean content of $56.35 \mu \mathrm{g} / \mathrm{g}$ at Week 0 for the four cultivars.

Table 4. Phenolic acid profiles of four wheat varieties cultivars $(\mu \mathrm{g} / \mathrm{g})$ stored under different conditions and for different lengths of time.

\begin{tabular}{|c|c|c|c|c|c|c|c|c|}
\hline \multirow{2}{*}{ Cultivar } & \multirow{2}{*}{$\begin{array}{l}\text { Storage } \\
\text { Time }\end{array}$} & \multirow{2}{*}{$\begin{array}{l}\text { Storage } \\
\text { Condition }\end{array}$} & \multicolumn{6}{|c|}{ Phenolic Compounds } \\
\hline & & & $\begin{array}{c}p \text {-Hydroxybenzoic } \\
\text { Acid }\end{array}$ & Vanillic Acid & Syringic Acid & $p$-Coumaric Acid & Ferulic Acid & Sinapic Acid \\
\hline \multirow{7}{*}{ Verna } & Week 0 & & $18.76 \pm 0.05 a$ & $23.50 \pm 0.21 c$ & $13.13 \pm 0.96 \mathrm{~h}$ & $92.79 \pm 4.08 \mathrm{a}$ & $421.25 \pm 9.39 \mathrm{a}$ & $19.95 \pm 1.48 \mathrm{a}$ \\
\hline & & Air & $18.57 \pm 0.13 b$ & $16.80 \pm 0.09 \mathrm{~h}$ & $7.32 \pm 0.36 \mathrm{mno}$ & $65.75 \pm 4.14 c$ & $356.28 \pm 13.22 \mathrm{~cd}$ & $12.93 \pm 1.28 \mathrm{ef}$ \\
\hline & Week2 & Vacuum & $17.29 \pm 0.07 \mathrm{~d}$ & $17.27 \pm 0.15 \mathrm{~h}$ & $7.94 \pm 0.64 \mathrm{~m}$ & $57.46 \pm 4.12 \mathrm{e}$ & $373.77 \pm 9.55 \mathrm{bc}$ & $17.61 \pm 1.64 \mathrm{~b}$ \\
\hline & \multirow{2}{*}{ Week 4} & Air & $18.29 \pm 0.15 c$ & $28.73 \pm 0.09 \mathrm{a}$ & $19.32 \pm 0.41 \mathrm{c}$ & $70.45 \pm 4.42 \mathrm{~b}$ & $423.44 \pm 13.09 \mathrm{a}$ & $17.03 \pm 1.02 \mathrm{~b}$ \\
\hline & & Vacuum & $17.1 \pm 0.05 \mathrm{e}$ & $23.73 \pm 0.72 \mathrm{c}$ & $14.04 \pm 0.39 \mathrm{fg}$ & $66.73 \pm 2.86 \mathrm{bc}$ & $354.28 \pm 14.51 \mathrm{~cd}$ & $13.87 \pm 0.56 \mathrm{de}$ \\
\hline & & Air & $17.13 \pm 0.03 \mathrm{de}$ & $24.72 \pm 0.17 \mathrm{~b}$ & $13.98 \pm 0.22 \mathrm{fg}$ & $63.29 \pm 2.59 \mathrm{~cd}$ & $386.04 \pm 8.90 \mathrm{~b}$ & $15.53 \pm 1.19 \mathrm{c}$ \\
\hline & Week 8 & Vacuum & $16.54 \pm 0.06 \mathrm{f}$ & $23.70 \pm 0.46 c$ & $14.39 \pm 0.40 \mathrm{ef}$ & $61.12 \pm 1.77 \mathrm{de}$ & $393.23 \pm 18.92 b$ & $15.26 \pm 1.58 \mathrm{c}$ \\
\hline \multirow{8}{*}{ Timilia } & Week 0 & & $13.52 \pm 0.08 \mathrm{~g}$ & $21.94 \pm 0.40 \mathrm{~d}$ & $11.81 \pm 0.24 \mathrm{ij}$ & $47.94 \pm 2.66 \mathrm{~g}$ & $343.60 \pm 17.88 \mathrm{~d}$ & $14.53 \pm 0.50 \mathrm{~cd}$ \\
\hline & & Air & $11.95 \pm 0.07 \mathrm{j}$ & $20.70 \pm 0.72 \mathrm{f}$ & $10.73 \pm 0.48 \mathrm{k}$ & $39.12 \pm 1.93 \mathrm{i}$ & $313.79 \pm 8.15 \mathrm{e}$ & $8.57 \pm 0.44 \mathrm{kl}$ \\
\hline & Week 2 & Vacuum & $10.13 \pm 0.06 \mathrm{~m}$ & $12.83 \pm 0.23 \mathrm{j}$ & $5.76 \pm 0.27 \mathrm{q}$ & $37.05 \pm 1.79 \mathrm{ij}$ & $307.89 \pm 3.41$ ef & $8.10 \pm 0.161$ \\
\hline & \multirow{2}{*}{ Week 4} & Air & $11.94 \pm 0.15 \mathrm{j}$ & $25.55 \pm 0.34 b$ & $16.95 \pm 0.36 \mathrm{~d}$ & $44.83 \pm 3.24 \mathrm{gh}$ & $374.18 \pm 8.85 \mathrm{bc}$ & $9.62 \pm 0.47 \mathrm{jk}$ \\
\hline & & Vacuum & $10.78 \pm 0.141$ & $21.81 \pm 0.21 \mathrm{de}$ & $13.52 \pm 0.46 \mathrm{gh}$ & $38.35 \pm 1.86 \mathrm{i}$ & $293.08 \pm 13.81 \mathrm{efg}$ & $7.29 \pm 0.251$ \\
\hline & & Air & $11.77 \pm 0.13 \mathrm{jk}$ & $22.31 \pm 0.41 \mathrm{~d}$ & $12.37 \pm 0.40 \mathrm{i}$ & $37.23 \pm 2.80 \mathrm{ij}$ & $311.91 \pm 11.73 \mathrm{e}$ & $9.93 \pm 0.25$ hijk \\
\hline & Week 8 & Vacuum & $11.73 \pm 0.22 \mathrm{k}$ & $23.80 \pm 0.49 c$ & $14.95 \pm 0.42 \mathrm{e}$ & $40.54 \pm 2.57 \mathrm{hi}$ & $353.50 \pm 17.37 \mathrm{~cd}$ & $11.28 \pm 0.63 \mathrm{gh}$ \\
\hline & Week 0 & & $12.63 \pm 0.09 \mathrm{~h}$ & $11.95 \pm 0.37 \mathrm{j}$ & $7.39 \pm 0.55 \mathrm{mn}$ & $46.32 \pm 1.27 \mathrm{~g}$ & $350.32 \pm 13.05 \mathrm{~d}$ & $15.50 \pm 0.50^{\circ} \mathrm{c}$ \\
\hline \multirow{6}{*}{ Sagittario } & & Air & $12.21 \pm 0.05 \mathrm{i}$ & $14.93 \pm 0.13 \mathrm{i}$ & $11.24 \pm 0.37 \mathrm{jk}$ & $40.84 \pm 1.65 \mathrm{hi}$ & $340.77 \pm 15.67 \mathrm{~d}$ & $10.02 \pm 0.46$ hijk \\
\hline & Week 2 & Vacuum & $4.54 \pm 0.05 \mathrm{~s}$ & $4.55 \pm 0.07 \mathrm{~m}$ & $6.56 \pm 0.66 \mathrm{op}$ & $33.75 \pm 2.03 \mathrm{jk}$ & $314.41 \pm 5.91 \mathrm{e}$ & $0.77 \pm 0.03 \mathrm{~m}$ \\
\hline & \multirow{2}{*}{ Week 4} & Air & $11.94 \pm 0.12 \mathrm{j}$ & $12.64 \pm 0.56 j$ & $7.15 \pm 0.27 \mathrm{mno}$ & $44.95 \pm 1.52 \mathrm{gh}$ & $311.66 \pm 10.87 \mathrm{e}$ & $10.22 \pm 0.84 \mathrm{hij}$ \\
\hline & & Vacuum & $11.82 \pm 0.11 \mathrm{jk}$ & $21.85 \pm 0.19 \mathrm{de}$ & $21.42 \pm 0.57 \mathrm{ab}$ & $40.30 \pm 2.31 \mathrm{i}$ & $351.91 \pm 14.21 \mathrm{~cd}$ & $9.75 \pm 0.16 \mathrm{jkl}$ \\
\hline & & Air & $12.64 \pm 0.06 \mathrm{~h}$ & $21.80 \pm 0.27 \mathrm{de}$ & $20.98 \pm 0.41 \mathrm{~b}$ & $44.99 \pm 1.42 \mathrm{gh}$ & $389.95 \pm 13.53 \mathrm{~b}$ & $13.34 \pm 0.79 \mathrm{def}$ \\
\hline & Week 8 & Vacuum & $12.54 \pm 0.06 \mathrm{~h}$ & $21.84 \pm 1.32 \mathrm{de}$ & $21.96 \pm 0.24 \mathrm{a}$ & $52.06 \pm 0.81 \mathrm{f}$ & $373.59 \pm 13.80 \mathrm{bc}$ & $12.43 \pm 0.64 \mathrm{fg}$ \\
\hline \multirow{7}{*}{ Claudio } & Week 0 & & $10.21 \pm 0.04 \mathrm{~m}$ & $18.20 \pm 0.99 \mathrm{~g}$ & $5.98 \pm 0.24 \mathrm{pq}$ & $38.33 \pm 1.67 \mathrm{i}$ & $307.04 \pm 4.13$ ef & $9.85 \pm 0.28$ hijk \\
\hline & Whe & Air & $7.14 \pm 0.05 \mathrm{q}$ & $10.93 \pm 0.35 \mathrm{k}$ & $3.80 \pm 0.12 \mathrm{r}$ & $33.22 \pm 1.40 \mathrm{jkl}$ & $290.56 \pm 17.61 \mathrm{efg}$ & $8.23 \pm 0.391$ \\
\hline & Week 2 & Vacuum & $6.56 \pm 0.09 \mathrm{r}$ & $9.09 \pm 0.791$ & $3.32 \pm 0.13 \mathrm{~s}$ & $24.75 \pm 1.58 \mathrm{n}$ & $287.65 \pm 7.19 \mathrm{fg}$ & $11.34 \pm 0.94$ gh \\
\hline & \multirow{2}{*}{ Week 4} & Air & $8.58 \pm 0.10 \mathrm{n}$ & $20.89 \pm 0.98$ ef & $9.65 \pm 0.391$ & $37.60 \pm 2.95 \mathrm{ij}$ & $336.73 \pm 12.61 \mathrm{~d}$ & $9.74 \pm 0.44 \mathrm{jkl}$ \\
\hline & & Vacuum & $7.36 \pm 0.09 p$ & $18.48 \pm 0.70 \mathrm{~g}$ & $7.85 \pm 0.42 \mathrm{~m}$ & $28.33 \pm 0.75 \mathrm{mn}$ & $304.35 \pm 5.71 \mathrm{ef}$ & $9.76 \pm 0.28 \mathrm{jkl}$ \\
\hline & \multirow{2}{*}{ Week 8} & Air & $8.42 \pm 0.06 \mathrm{n}$ & $16.65 \pm 0.39 \mathrm{~h}$ & $6.69 \pm 0.37$ nop & $29.32 \pm 1.24 \mathrm{~lm}$ & $299.11 \pm 14.14 \mathrm{ef}$ & $11.15 \pm 0.67 \mathrm{ghi}$ \\
\hline & & Vacuum & $7.86 \pm 0.14 \mathrm{o}$ & $17.20 \pm 0.77 \mathrm{~h}$ & $7.34 \pm 0.48 \mathrm{mno}$ & $31.71 \pm 1.84 \mathrm{klm}$ & $273.04 \pm 12.24 \mathrm{~g}$ & $9.97 \pm 0.54$ hijk \\
\hline
\end{tabular}

Data are expressed as mean \pm SD $(n=3)$. Values in the column with different letters are significantly different at $p<0.05$.

The amount of phenolic acid, $p$-hydroxybenzoic acid, decreased significantly after 8 weeks of storage in all cultivars, except in Sagittario. The least reduction in $p$-hydroxybenzoic acid was shown in Verna stored in air, which decreased to $8.67 \%$. $p$-coumaric acid also decreased over storage for 8 weeks, except in Sagittario, which was stored under vacuum. In Verna, $p$-coumaric acid was very unstable and was shown to decrease up to $34.13 \%$ over 8 weeks. Decreases in ferulic acid were shown in Verna, Timilia, and Claudio, but more than $88.93 \%$ remained after 8 weeks. Meanwhile, there was an increase in Sagittario after storage for 8 weeks with respect to ferulic acid. The losses of sinapic acid were significantly found in all cultivars from freshly prepared flour to the 8th week, except Claudio. The biggest loss of sinapic acid was shown in Timilia stored in air, which was up to $31.61 \%$ over the 8-week period. On the contrary, an increase was shown in vanillic acid and syringic acid from Week 0 to Week 8 in all the other three cultivars, with the exception of Claudio. In particular, an increase in the syringic acid up to $297.03 \%$ was detected in Sagittatio under vacuum storage for 8 weeks. The concentration of individual phenolic acids was shown to decline or increase at different rates, possibly due to their chemical structure, biochemical pathway relationship, and storage conditions.

\subsection{Antioxidant Activity}

\subsubsection{DPPH Assay}

The initial antioxidant activity values of the four cultivars determined by the DPPH assay ranged from 6.78 to $7.87 \mu \mathrm{mol}$ trolox/g. Verna showed the best antioxidant activity compared to the remaining cultivars (Figure 1). 


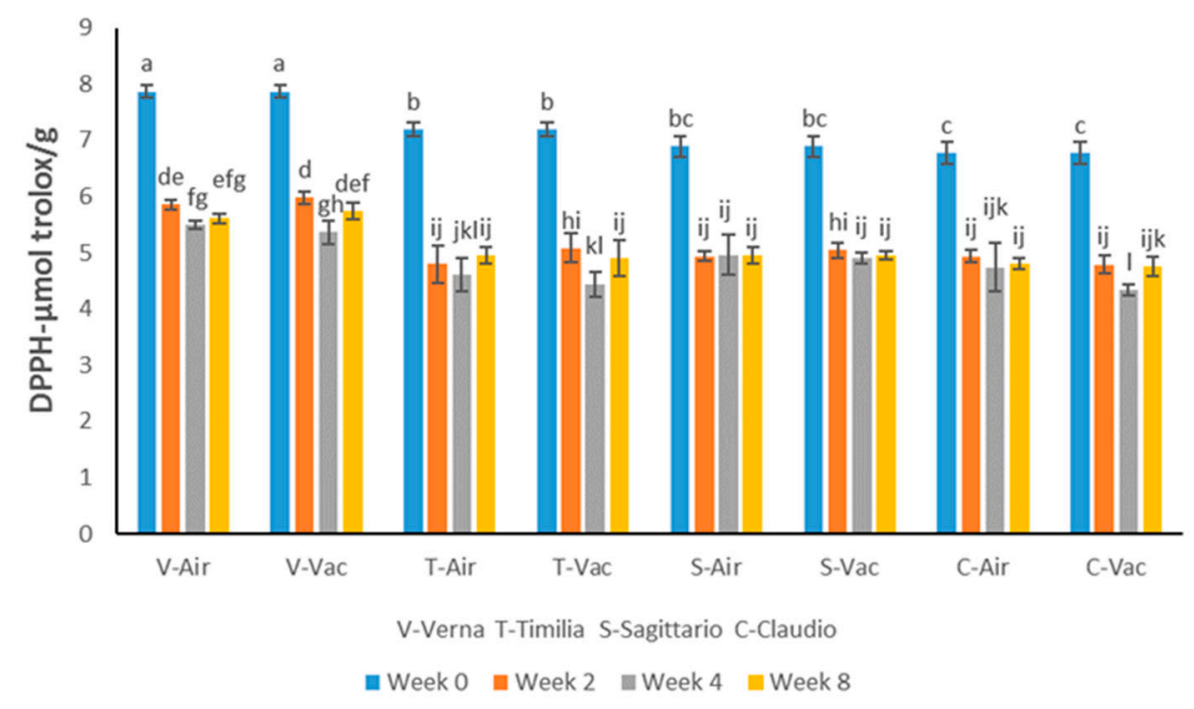

Figure 1. Antioxidant activity shown by DPPH assay of four wheat cultivars storage in different conditions and for different lengths of time. Different letters show significant differences at $p<0.05$.

The antioxidant activity shown by the DPPH assay of the four cultivars decreased significantly after 8 weeks of storage. However, there was no significant difference between the air and vacuum storage conditions regarding the DPPH values. In air, the decreases were $28.72,31.25,28.16$, and $29.20 \%$ in Verna, Timilia, Sagittario, and Claudio, respectively, over the 8-week period. Regarding the vacuum condition, the decrease was 27.06, 31.94, 28.16 , and $29.79 \%$ in the four cultivars, respectively. The DPPH antioxidant activity in Verna storage under vacuum decreased the least among the four cultivars. Approximately $72.94 \%$ of the antioxidant activity was maintained in Verna after the 8-week storage period.

\subsubsection{FRAP Assay}

The initial antioxidant activity values of the four cultivars determined by the FRAP assay ranged from 2.18 to $2.57 \mathrm{mmol} \mathrm{Fe}{ }^{2+} / 100 \mathrm{~g}$. Verna showed a higher antioxidant activity than the other three cultivars, as represented by the FRAP assay (Figure 2).

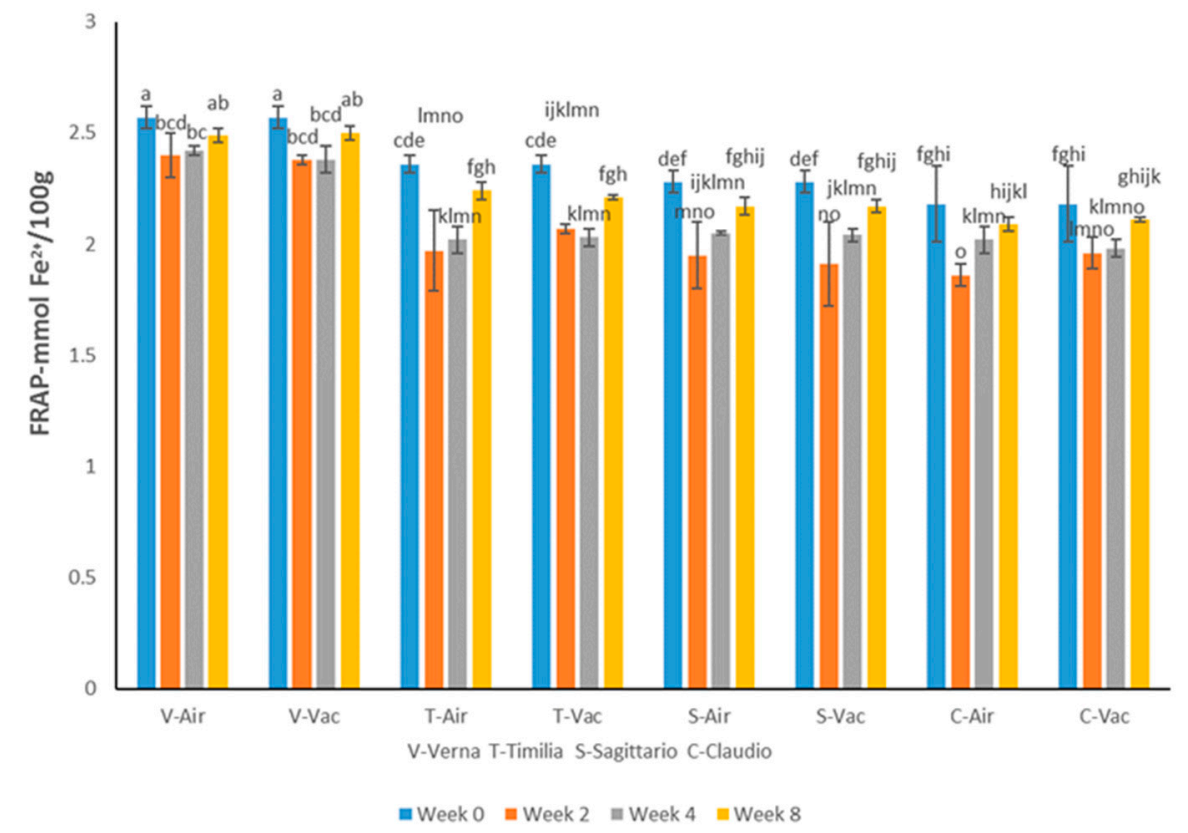

Figure 2. Antioxidant activity shown by the FRAP assay of four wheat cultivars storage in different conditions for different lengths of time. Different letters show significant difference at $p<0.05$. 
The ability of wheat polyphenol to reduce $\mathrm{Fe}^{3+}$ to $\mathrm{Fe}^{2+}$ was not significantly affected by either storage conditions or time over the 8-week storage period for all the four cultivars. There was a reduction in antioxidant activity after Week 2 but a recovery at the end of the storage period.

\section{Discussion}

In the present study, we investigated the moisture content, phenolic acids profile, TPC, TFC, and AA of the whole wheat flour extracts of four cultivars, Verna, Timilia, Sagittario, and Claudio, from same harvest year and same farm in Italy. Different cultivars of wheat showed different levels of TPC, TFC, and AA as well as phenolic acids profile during the entire storage period as well as under the two storage conditions. The wheat polyphenol was influenced more by storage time $(0,2,4,8$ weeks) than storage conditions (aerated and under vacuum).

\subsection{Moisture Content}

The flours of the four cultivars under vacuum storage had a stable moisture content without contact with water and oxygen. However, the moisture content decreased from week 0 to week 4 for the four cultivars stored in the air, and then there was an increase from the 4 th week to the 8 th week. There was also an increase observed in the TFC and AA, as determined by the DPPH assay in the same period. This indicated that moisture content is a key factor affecting the stability of some phenolic compounds during storage.

\subsection{Total Polyphenol and Antioxidant Activity}

As reported by Silvestro [4], wheat cultivar affected the TPC of bound forms and the AA determined by FRAP. Differences in TPC and AA among the four cultivars of wheat were also observed in our study. Verna exhibited a higher amount of TPC, TFC, and AA than Timilia, Sagittario, and Claudio in freshly prepared flour under the two storage conditions. Timilia was characterized by the second highest total amount of TPC. Regarding TFC, Timilia and Sagittario were significantly higher than Claudio. With respect to AA, there was no significant difference among Timilia, Sagittario, and Claudio in freshly prepared flour.

The results of our study showed that storage time significantly influenced the phenolic contents in whole wheat flour. After 8 weeks of storage, the TPC, TFC, and AA of all the cultivars decreased when compared to the freshly prepared flour. This may be attributed to the oxidation of polyphenols [10]. Similar results were reported by Oliveira et al. [11], who showed a reduction in sorghum flour after 60 days of storage. Verna was characterized by smaller losses of TPC and TFC than the other three cultivars over 8 weeks. In addition, Verna showed the highest retention of AA represented in DPPH among four cultivars of about $73 \%$. With respect to the TPC and TFC, the biggest reduction was found in Claudio compared to the freshly prepared flour. Regarding the AA represented in DPPH, Timilia showed a lower retention than other three cultivars over 8 weeks. In fact, a sharp increase in TFC from the 4th to the 8 th week was reported in this study. It is feasible that unstable glycosides may have been transformed, resulting in an increase in TFC. Similarly, AA represented by the DPPH assay resulted in a significant increase during the same period. It seems that the decrease in AA did not follow the reduction in the polyphenol content of whole wheat flour. In similar findings in the research of Patthamakanokporn et al. [21], a continuous decrease in TPC was found in homogenized guava, but the FRAP antioxidant activity did not decrease during the 3-month storage. A possible reason for this was that the antioxidant activity was not related to an individual phenolic or classes of phenolics but to a synergistic effect between different classes of polyphenol.

However, the AA determined by the FRAP assay was different with the DPPH assay. Different antioxidants have different mechanisms against free radicals [22], and probably different polyphenol molecules in wheat were responsible for the differences in FRAP and DPPH. Liu et al. [23] found that the total phenolic contents showed a higher correlation 
with antioxidant capacity when using FRAP assays than when using the DPPH assay among the fruits and vegetables analyzed. A reduction was shown at the 2 nd week but a recovery was shown at the 8th week in the FRAP assay in our study. In fact, the decreases in the total polyphenol contents were not always influenced by AA [20]; the oxidation of polyphenol was expected to result in a lower antioxidant capacity, but the formation of new antioxidant polymers or degradation products of phenolics also had AA [24]. In addition, the phenolic profile may be changed during storage, as some phenolics could be degraded while other new phenolics could be formed [25]. This could also increase the TPC and compensate for the loss of AA from the degraded compounds. According to Flores et al. [26], an improvement in TPC and a slight increase in AA in spray-dried blueberry pomace extract were observed after a 40-day storage. It is possible to explain this by some phenolic compounds being newly produced during the storage time. Some reports have shown that anthocyanins could decompose to benzoic acid derivatives such as syringic acid or 4-hydroxybenzoic acid [27,28].

Vacuum conditions were supposed to be stable without contact with water and oxygen. However, the results were different from the hypothesis, as most of the mean values for the assessed parameters except for the moisture content of the four cultivars were not able to significantly discriminate between storage in air and under vacuum in our research, which was similar to the results reported by Ghirardello et al. [25]. The latter were not able to detect significant difference among storage conditions (ambient air, vacuum, or modified atmosphere) regarding the loss of TPC and AA in hazelnuts (Corylus avellana L.) after 12 months of storage.

\subsection{Phenolic Acids Profile}

Ferulic acid and $p$-coumaric acid were the principle phenolic acid components of the four cultivars, as reported previously by Loreto et al. [5]. The highest ferulic acid content was reported for Verna, which is lower than that in the study of Gottia et al. [7]. The ferulic acid content from Claudio was higher than that reported by Loreto et al. [5].These differences may be due to the difference in harvest year, storage conditions, and other environmental factors.

To the best of our knowledge, no data are available regarding the effect of different storage times and conditions on changes in the phenolic acid profiles of whole wheat flour. The storage time influenced the concentration of each phenolic acid, but it was difficult to compare within different storage conditions in our study. Sinapic acid and $p$-coumaric acid were significantly decreased in most of the wheat flours over the 8-week storage period. However, there was an increase in vanillic acid and syringic acid during this period. Differences could possibly be explained by the different rates of degradation and/or synthesis of each phenolic acid [25]. Different phenolic acids have different chemical structures and also present different structures in different fractions, such as free and bound phenolic fractions. Structural difference plays an important role in individual reducing capacity [29]. The storage process changes the content of phenolic acids in the plant material, and decreases or increases in their content were both observed [30]. Zhou et al. [29] found a reduction in the concentration of ferulic acids from brown rice after storage for 6 months. According to Bolling et al. [31], there were dynamic metabolic processes affecting phenolic acid content during storage, including an increase in polyphenol extractability; the degradation of polymeric polyphenols; and, consequently, an increase in soluble phenolics during storage. In addition, this was possibly attributable to a biosynthesis pathway of these six phenolic acids in plants [5,7]. For example, $p$-coumaric acid could be converted to ferulic acid and $p$-hydroxybenzoic acid, which could continue converting to vanillic acid. Similarly, ferulic acid could convert to sinapic acid and then syringic acid.

\section{Conclusions}

Most of the analyzed parameters illustrated differences in cultivars. Verna showed higher levels of TPC, TFC, and AA than Timilia, Sagittario, and Claudio during the entire 
storage period as well as under the two storage conditions. The phenolic content of whole wheat flour was not affected by the storage conditions-in fact, no significant differences between air and vacuum conditions were detected. Some reductions in total polyphenol were observed after storage for 8 weeks. The moisture content, flavonoid content, and antioxidant potential were decreased after 8 weeks of storage compared to freshly prepared flour, but a small increase between 4th and 8th week was also detected. Some changes, either decrease or increase in the concentration regarding the phenolic acids, were shown, and no compound was completely degraded during storage. Overall, our results firstly illustrated that the storage time significantly influenced the polyphenol content and profile, but we were not able to significantly discriminate between storage in air and under vacuum. Further knowledge in this area will be useful in determining the proper length and method of storage as well as the selection of cultivar in order for whole wheat flour to retain its bioactive compounds for benefits when consumed in daily life.

Author Contributions: Conceptualization, F.T. and G.D.; methodology, F.T. and G.D.; software, Y.Z.; formal analysis, Y.Z. and E.D.; investigation, Y.Z.; data curation, Y.Z. and F.T.; writing-original draft preparation, Y.Z.; writing - review and editing, Y.Z. and F.T.; visualization, Y.Z.; supervision, F.T. and G.D.; project administration, F.T.; funding acquisition, F.T. and G.D. All authors have read and agreed to the published version of the manuscript.

Funding: This research was funded by University di Bologna, RFO funds to G.D.

Institutional Review Board Statement: Not applicable.

Informed Consent Statement: Not applicable.

Data Availability Statement: The data that supported the findings of the present study are available from the corresponding author upon request.

Conflicts of Interest: The authors declare no conflict of interest.

\section{References}

1. Di Silvestro, R.; Marotti, I.; Bosi, S.; Bregola, V.; Carretero, A.S.; Sedej, I.; Mandic, A.; Sakac, M.; Dinelli, G. Health-promoting phytochemicals of Italian common wheat varieties grown under low-input agricultural management ${ }^{\dagger}$. J. Sci. Food Agric. 2012, 92, 2800-2810. [CrossRef]

2. Chen, Z.; Wang, P.; Weng, Y.; Ma, Y.; Gu, Z.; Yang, R. Comparison of phenolic profiles, antioxidant capacity and relevant enzyme activity of different Chinese wheat varieties during germination. Food Biosci. 2017, 20, 159-167. [CrossRef]

3. Leoncini, E.; Prata, C.; Malaguti, M.; Marotti, I.; Segura-carretero, A.; Catizone, P.; Dinelli, G.; Hrelia, S. Phytochemical profile and nutraceutical value of old and modern common wheat cultivars. PLoS ONE 2012, 7, e45997. [CrossRef] [PubMed]

4. Di Silvestro, R.; Di Loreto, A.; Bosi, S.; Bregola, V.; Marotti, I.; Benedettelli, S.; Segura-Carretero, A.; Dinelli, G. Environment and genotype effects on antioxidant properties of organically grown wheat varieties: A 3-year study. J. Sci. Food Agric. 2017, 97, 641-649. [CrossRef] [PubMed]

5. Di Loreto, A.; Bosi, S.; Montero, L.; Bregola, V.; Marotti, I.; Sferrazza, R.E.; Dinelli, G.; Herrero, M.; Cifuentes, A. Determination of phenolic compounds in ancient and modern durum wheat genotypes. Electrophoresis 2018, 39, 2001-2010. [CrossRef]

6. Bresciani, L.; Scazzina, F.; Leonardi, R.; Dall'Aglio, E.; Newell, M.; Dall'Asta, M.; Melegari, C.; Ray, S.; Brighenti, F.; Del Rio, D. Bioavailability and metabolism of phenolic compounds from wholegrain wheat and aleurone-rich wheat bread. Mol. Nutr. Food Res. 2016, 60, 2343-2354. [CrossRef]

7. Gotti, R.; Amadesi, E.; Fiori, J.; Bosi, S.; Bregola, V.; Marotti, I.; Dinelli, G. Differentiation of modern and ancient varieties of common wheat by quantitative capillary electrophoretic profile of phenolic acids. J. Chromatogr. A 2018, 1532, 208-215. [CrossRef]

8. Vanlerberghe, G.C. Alternative oxidase: A mitochondrial respiratory pathway to maintain metabolic and signaling homeostasis during abiotic and biotic stress in plants. Int. J. Mol. Sci. 2013, 14, 6805-6847. [CrossRef]

9. Witkowska-Banaszczak, E.; Radzikowska, D.; Ratajczak, K. Chemical profile and antioxidant activity of Trollius europaeus under the influence of feeding aphids. Open Life Sci. 2018, 13, 312-318. [CrossRef]

10. Srivastava, A.; Akoh, C.C.; Yi, W.; Fischer, J.; Krewer, G. Effect of storage conditions on the biological activity of phenolic compounds of blueberry extract packed in glass bottles. J. Agric. Food Chem. 2007, 55, 2705-2713. [CrossRef]

11. De Oliveira, K.G.; Queiroz, V.A.V.; De Almeida Carlos, L.; De Morais Cardoso, L.; Pinheiro-Sant'Ana, H.M.; Anunciação, P.C.; De Menezes, C.B.; Da Silva, E.C.; Barros, F. Effect of the storage time and temperature on phenolic compounds of sorghum grain and flour. Food Chem. 2017, 216, 390-398. [CrossRef] [PubMed]

12. Lang, G.H.; Da Silva Lindemann, I.; Ferreira, C.D.; Fernanda, J.; Vanier, N.L.; De Oliveira, M. Effects of drying temperature and long-term storage conditions on black rice phenolic compounds. Food Chem. 2019, 287, 197-204. [CrossRef] [PubMed] 
13. Chiu, K.Y.; Chen, C.L.; Sung, J.M. Partial vacuum storage improves the longevity of primed sh-2 sweet corn seeds. Sci. Hortic. 2003, 98, 99-111. [CrossRef]

14. Dinelli, G.; Segura-Carretero, A.; Di Silvestro, R.; Marotti, I.; Arráez-Román, D.; Benedettelli, S.; Ghiselli, L.; Fernadez-Gutierrez A. Profiles of phenolic compounds in modern and old common wheat varieties determined by liquid chromatography coupled with time-of-flight mass spectrometry. J. Chromatogr. A 2011, 1218, 7670-7681. [CrossRef]

15. Singleton, V.L.; Orthofer, R.; Lamuela-Raventós, R.M. Analysis of total phenols and other oxidation substrates and antioxidants by means of folin-ciocalteu reagent. Methods Enzymol. 1999, 299, 152-178. [CrossRef]

16. Adom, K.K.; Liu, R.H. Antioxidant activity of grains. J. Agric. Food Chem. 2002, 50, 6182-6187. [CrossRef]

17. Truzzi, F.; Valerii, M.C.; Tibaldi, C.; Zhang, Y.; Abduazizova, V.; Spisni, E.; Dinelli, G. Are supplements safe? Effects of gallic and ferulic acids on in vitro cell models. Nutrients 2020, 12, 1591. [CrossRef]

18. Floegel, A.; Kim, D.O.; Chung, S.J.; Koo, S.I.; Chun, O.K. Comparison of ABTS/DPPH assays to measure antioxidant capacity in popular antioxidant-rich US foods. J. Food Compos. Anal. 2011, 24, 1043-1048. [CrossRef]

19. Benzie, I.F.F.; Strain, J.J. The ferric reducing ability of plasma (FRAP) as a measure of "antioxidant power": The FRAP assay. Anal. Biochem. 1996, 239, 70-76. [CrossRef]

20. Rocha-Parra, D.F.; Lanari, M.C.; Zamora, M.C.; Chirife, J. Influence of storage conditions on phenolic compounds stability, antioxidant capacity and colour of freeze-dried encapsulated red wine. LWT Food Sci. Technol. 2016, 70, 162-170. [CrossRef]

21. Patthamakanokporn, O.; Puwastien, P.; Nitithamyong, A.; Sirichakwal, P. Changes of antioxidant activity and total phenolic compounds during storage of selected fruits. J. Food Compos. Anal. 2008, 21, 241-248. [CrossRef]

22. Amorati, R.; Valgimigli, L. Methods to measure the antioxidant activity of phytochemicals and plant extracts. J. Agric. Food Chem. 2018, 66, 3324-3329. [CrossRef] [PubMed]

23. Liu, C.; Zhao, Y.; Li, X.; Jia, J.; Chen, Y.; Hua, Z. Antioxidant capacities and main reducing substance contents in 110 fruits and vegetables eaten in China. Food Nutr. Sci. 2014, 5, 293-307. [CrossRef]

24. Kallithraka, S.; Salacha, M.I.; Tzourou, I. Changes in phenolic composition and antioxidant activity of white wine during bottle storage: Accelerated browning test versus bottle storage. Food Chem. 2009, 113, 500-505. [CrossRef]

25. Ghirardello, D.; Bertolino, M.; Belviso, S.; Dal Belloa, B.; Giordanoa, M.; Luca, R.; Gerbia, V.; Antonuccib, M.; Spigolonb, N.; Zeppaaet, G. Phenolic composition, antioxidant capacity and hexanal content of hazelnuts (Corylus avellana L.) as affected by different storage conditions. Postharvest Biol. Tecnol. 2016, 112, 95-104. [CrossRef]

26. Flores, F.P.; Singh, R.K.; Kong, F. Physical and storage properties of spray-dried blueberry pomace extract with whey protein isolate as wall material. J. Food Eng. 2014, 137, 1-6. [CrossRef]

27. De Villiers, A.; Cabooter, D.; Lynen, F.; Desmet, G.; Sandra, P. High performance liquid chromatography analysis of wine anthocyanins revisited: Effect of particle size and temperature. J Chromatogr. A 2009, 1216, 3270-3279. [CrossRef]

28. Patras, A.; Brunton, N.P.; O'Donnell, C.; Tiwari, B.K. Effect of thermal processing on anthocyanin stability in foods; mechanisms and kinetics of degradation. Trends Food Sci. Technol. 2010, 21, 3-11. [CrossRef]

29. Zhou, Z.; Chen, X.; Zhang, M.; Blanchard, C. Phenolics, flavonoids, proanthocyanidin and antioxidant activity of brown rice with different pericarp colors following storage. J. Stored Prod. Res. 2014, 59, 120-125. [CrossRef]

30. Amarowicz, R.; Carle, R.; Dongowski, G.; Alessandra, D.; Rudolf, G.; Dietmar, K.; Guiseppe, M.; Mariusz, K.P. Influence of postharvest processing and storage on the content of phenolic acids and flavonoids in foods. Mol. Nutr. Food Res. 2009, 53, S151-S183. [CrossRef]

31. Bolling, B.W.; Blumberg, J.B.; Chen, C.-Y.O. The influence of roasting, pasteurization, and storage on polyphenols content and antioxidant capacity of California almond skins. Food Chem. 2010, 123, 1040-1047. [CrossRef] [PubMed] 